\title{
How Culture Comes to Mind: From Social Affordances to Cultural Analogies
}

\author{
Laurence Kaufmann* \& Fabrice Clément*
}

"L'anthropologie, même sociale, se proclame solidaire de l'anthropologie physique, dont elle guette les découvertes avec une sorte d'avidité. Car même si les phénomènes sociaux doivent être provisoirement isolés du reste et traités comme s'ils relevaient d'un niveau spécifique, nous savons bien qu'en fait et même en droit l'émergence de la culture restera pour l'homme un mystère tant qu'il ne parviendra pas à déterminer, au niveau biologique, les modifications de structure et de fonctionnement du cerveau, dont la culture a été simultanément le résultat naturel et le mode d'appréhension »

Claude Lévi-Strauss, Leçon inaugurale au Collège de France, 1960

\begin{abstract}
RESUME : Comment la culture vient à l'esprit. Des affordances sociales aux analogies culturelles. Jusqu'à présent, les tentatives naturalistes visant à rendre compte des phénomènes culturels ont eu tendance à les appréhender comme des représentations qui se diffusent dans la population grâce à leurs propriétés contreintuitives, qui retiennent l'attention et facilitent la mémorisation individuelle. En complément à cette perspective, qui présuppose une forme de distanciation cognitive entre les individus et leur culture, cet article propose un modèle naturaliste qui prend acte de la forte implication cognitive et de la posture, non pas contemplative mais participative, que provoquent bon nombre de phénomènes culturels. Un tel modèle tente de défendre une «vision continuiste» du lien entre nature et culture en remettant partiellement en question la focalisation traditionnelle des sciences sociales sur la dimension artificielle et arbitraire des faits sociaux. Pour les auteurs, en effet, cette focalisation ne rend pas compte de la naturalité et de l'universalité d'un certain nombre de formes sociales élémentaires. Une fois posée la naturalité partielle du social, l'objectif est alors de rendre compte de l'émergence des phénomènes culturels. L'hypothèse défendue ici est que les capacités analogiques, elles aussi naturelles, qui permettent aux esprits humains de «dériver» les formes culturelles du monde de la nature, qu'il soit physique ou social, jouent un rôle central dans l'élaboration d'une sphère de l'expérience collective qui est tout à la fois culturelle et intuitive.
\end{abstract}

MoTS-CLE : Analogie, culture, cognition, forme sociale, naturalisme, affordance, idéologie.

ABSTRACT: Until now, the naturalist attempts to account for cultural phenomena have tended to see them as representations that spread within the population thanks to the counterintuitive properties making them salient and easy to remember. As a

* Professeur FNS, Département de sociologie, Université de Genève, Suisse. fabrice.clement@socio.unige.ch

- Professeure ordinaire, Faculté des Sciences Sociales et Politiques, Université de Lausanne, Suisse. laurence.kaufmann@unil.ch

(C) 2008 Association pour la Recherche Cognitive. 
supplement to this view, which postulates a kind of cognitive distance between individuals and culture, this paper proposes a naturalist model that takes into consideration the strong cognitive involvement and the participative rather than contemplative stance triggered by a good many cultural phenomena. Such a model tries to defend a «continuist view» of the link between nature and culture by calling partially into question the traditional emphasis of social sciences on the artificial, arbitrary dimension of social facts. For the authors, indeed, this emphasis does not account for the naturality and universality of a certain number of elementary social forms. Once the partial naturality of the social is asserted, the purpose is to describe the emergence of cultural phenomena. The hypothesis put forward here is that analogical capacities, also natural, which allow human minds to «draw» cultural forms from the world of nature, either physical or social, play a central role in the elaboration of a sphere of collective experience that is both cultural and intuitive.

KEY WORDS: Analogy, culture, cognition, social form, naturalism, affordance, ideology

\section{INTRODUCTION $^{1}$}

For most anthropologists, culture covers different kinds of phenomena, ranging from habits to institutions. Culture, as Edward Tylor put it, "is a complex whole which includes knowledge, belief, art, morals, law, custom, and any other capabilities and habits acquired by man as a member of society" (Tylor, 1958, p. 1). Far from the evolutionary definition of culture as welladaptative information transmitted through nongenetic means among members of a group (Boesch \& Tomasello, 1998), the anthropological view of culture sees variation as going beyond anything that might arise from the course of biological evolution (Carrithers, 1997, p. 99). Cultural anthropology, in particular, insists on the "superorganic" dimension of culture and on the complexity of representational, human-specific creations (i.e. myths, rituals, symbols). This being so, such emphasis on cultural variation as the main characteristic of socio-cultural phenomena is not shared by all anthropological perspectives (for a review, see Atran et al., 2005). Contrary to cultural anthropology, indeed, social anthropology, which dwells on the social dimensions of human groupings (i.e. kinship, political organization, economic exchange), tends to emphasize the organizational aspects of the socio-cultural phenomena that are recurrent - not to say universal - in any society.

In this paper, we will try to give a naturalistic twist to those two different anthropological perspectives by defending a type of moderate naturalism that preserves both ontological and cognitive continuity between nature and culture as far as possible. To do so, we will call into question the automatic association, shared by both naturalist and culturalist views of culture, between natural and material on the one hand, and cultural and arbitrary on the other hand. In fact, in the radical naturalist view, culture is mostly regarded as an epiphenomenal, counterintuitive set of discrete representational contents, isolated from one another, and characterized by their intrinsic properties - mainly systematic violation of hard-wired expectations about object boundaries and movements (naive physics), species configurations and relationships (naive biology), and goal-directed and interactive behavior (naive psychology)

${ }^{1}$ This project was supported by the Swiss National Science Foundation (SNSF). Some aspects of this work have benefited from insightful discussions with Lawrence Hirschfeld, with whom our reflections on the role of analogy-making in culture have started. His ideas on naive sociology have also been decisive on our own line of reasoning on this matter. 
(Sperber, 1975, 1996; Boyer, 1994; Atran, 2001). In the radical culturalist view, by contrast, culture is seen as a floating shared system of symbols, that is, a system of immaterial, artificial signs which is characterized by its arbitrariness and its independence from lower-level phenomena (Geertz, 1973; Clifford, 2002). Our working hypothesis goes partially counter to those predominant views, since it postulates that culture is certainly artificial but not necessarily arbitrary or counterintuitive. Instead of insisting on the arbitrariness of culture, which leads to an increasing of the gap between natural mechanisms and sociocultural constructs, the moderate naturalism that we want to propose tries to integrate them into an ontological and epistemological continuum. On the ontological side, indeed, the gap between nature and culture decreases in a significant way if we consider cultural objects to supervene, at least to a certain extent, upon invariant, elementary social forms that are characterized by their tangibility and universality (Kaufmann \& Clément, 2003). On the epistemological side, the cognitive discontinuity between two impervious layers of cognition, that is, intuitive, experiential cognition and symbolic, ideological cognition, partly yields to cognitive continuity if we consider the bridgebuilding work of analogical mappings.

The somewhat risky challenge that we want to take up in this paper is to argue in favor of this twofold hypothesis. In the first step, we will adopt as our own the emphasis of social anthropology on the invariant features of social groupings while making it compatible with the long-term evolution of social species (part I). From the point of view of social naturalism that we want to defend here, social forms are indeed considered as cross-cultural saliencies that stand out in the experiential, perceptual and action fields of any well-adapted, evolved social organism. In the second step, we will try to take into account, along the same lines as cultural anthropology, human-specific creativity by hypothesizing the existence of a socio-cognitive mechanism, namely analogymaking, which contributes to the creation and maintenance of the symbolic components of culture (part II). Insofar as analogies refer both to a specific kind of cognitive processing and to typical items of human culture, they play a central role in our naturalist framework.

\section{ONTOLOGICAL AND EPISTEMOLOGICAL PERSPECTIVES ON SOCIAL FACTS}

\section{A moderate naturalism}

The moderate naturalism we want to advocate here defends the autonomy of social facts while carving out a place for them in the natural world. Such a modest naturalism has three main characteristics. First, it gives up determining once and for all the ontological unit of culture, whether it be infra-intentional states, voluntary acts, social relationships or symbolic contents, and accepts the integration of different levels of description within the same naturalistic framework. Therefore, the naturalist framework we want to propose does not involve reductionism, that is, the a priori principle that everything in nature can be reduced to the ultimate constituents of matter. As Mayr (2004) put it, adopting an analytical method in order to identify the fundamental elements of a system is different from the reductionist claim that those very elementary units do explain the system as a whole. Second, in line with social naturalism as initiated by George Mead, Erving Goffman and John Dewey and recently discussed by contemporary sociologists (Quéré, 2001, 2002; Conein, 2001; Céfaï, 2001), it assumes that social theorizing should be grounded in methods 
of inquiry continuous with those successful in the natural sciences, mainly observational methods. Last but not least, this moderate naturalism denies the relevance of what we could call, by analogy with the well-known mind-body problem, the mind-culture problem that haunts both strong naturalism and culturalism: is it mind that causes culture or culture that causes mind? In fact, such mind-culture framing is misleading: it supposes that efficient causation is the only remaining ontological link able to prevent cultural phenomena from an autonomization that would be synonymous with a parallel, immaterial world. Traditionally, the paradigm of efficient causation is that of billiard balls; a billiard ball provokes the movement and hence the trajectory of another one by bumping into it. The causal link connecting the antecedent and consequent events is physical and implies the existence of two a priori separated entities, in this case two billiard balls. When applied to the link between mind and culture, this "push-pull" framing has counterproductive implications: it considers mind and culture as empirical entities, a priori separated by a gap that must be filled in by some ontological glue, namely physical causation. Now from an evolutionary point of view, it does not make much sense to draw an external, causal relationship between mind and culture: rather, within the ecological niche they are both part of, they are related by the internal connection, the "generic ontological dependence" that characterizes, as Esfeld (1998, p. 367) put it, the parts or the levels of a given holistic system. From this "ecological" perspective, the supposedly mind-culture causal link yields to an internal relationship between what we could consider as two different levels of the same "mind". (1) The basic-level, pre-wired mind on which cognitive science is focused is the site of the organized set of universal cognitive devices that evolved as an adaptation to the specific challenges presented by the ancestral environment (Tooby \& Cosmides, 1992; Sperber \& Hirschfeld, 1999). (2) The high-level, sophisticated and human-specific mind on which social sciences dwell is a web of impersonal public meanings, concepts and rules, i.e. the "objective spirit" that Descombes (1996) speaks of.

As will be seen, one of the main difficulties is to specify how cognitive and cultural minds are related. Whereas counterintuitive models of culture tend to portray a two-layer, "split mind" that draws an impervious boundary between the cognitive primacy of basic-level experiences and well-controlled situated cultural evocations, our model emphasizes its intuitive counterpart by shedding light on the analogical connections which might bridge the gap between cognition and culture.

\section{From cognition to culture}

There is a tendency in contemporary cognitive science to think that natural selection gave priority to domain-specific information and learning processing over domain-general mechanisms, which are too costly in terms of time and energy (Cosmides \& Tooby, 1994). From this evolutionary perspective, human learners have pre-wired specific learning mechanisms that allow them to grasp the regularities of their environment by focusing on domain-relevant aspects of data (Gelman \& Williams, 1998). Natural selection is said to favor domainspecific processing of data in core domains of knowledge, named according to the different kinds of ontological 'objects' and causality principles implied: "naive physics" (physical entities) (Baillargeon, 1987; Spelke, 1994), "naive biology" (living beings) (Atran, 1990; Keil, 1989), "naive psychology" (mental states) (Wellman, 1990), and "naive arithmetic" (small numbers) (Spelke \& Dehaene, 1999). Work on domain-specificity thus reveals how children's 
knowledge about objects and events expands at a terrific rate from the very first months of infancy, including causal expectations that are obviously underdetermined by experience (Hirschfeld and Gelman, 1994).

As interesting it might be, this evolutionary conception raises two problems relevant to our inquiry. First, the division of cognitive labor that it puts forward does not take into account "naive sociology" (Hirschfeld, 1995, 1996; Jackendoff, 1992), that is, the way in which evolved social species process the affiliations, regularities and relationships structuring their social environment. And yet, the speculative reasoning that evolutionary psychology applies to other ontological domains, such as the physical or the biological domain, can also be applied to the social environment. The highly demanding, problemgenerating physical and social environment our ancestors lived in must have fostered the development of well-adapted cognitive devices, including abilities specifically dedicated to the selection and storage of relevant social information. Given the importance of social coordination, group membership, and cooperation for evolved animals' survival, they have most likely favored the emergence of domain-specific abilities (cf. Hirschfeld, this volume). Evolved social beings can be assumed to be internally prepared to grasp and deal with the expectable, elementary social regularities that emerge from the intricate chain of action-reaction, ensuring, as Park (1936) put it, the ecological balance of society. Second, such a mainstream evolutionist conception leaves mostly unexplained the processing of cultural information. However, if one takes seriously the evolutionary argument, one can indeed suppose that culture must have co-evolved with the cognitive abilities and facilitators necessary for its learning and maintenance. Our hypothesis is that analogy-making is one of those cognitive abilities, essential for ensuring the informational match between mind and culture ${ }^{2}$. Analogical mappings, which are simultaneously a specific kind of cognitive processing and the relatively autonomous cultural products of this processing, are indeed a natural way for our brains to process information $^{3}$. Analogical thinking picks out patterns of relations, weaves together heterogeneous institutional and knowledge systems and finds common meaning in scattered, fragmentary events and representations (Hirschfeld, 2000). Cultural analogies enable us to detect commonality in the hidden underlying structure of different domains of knowledge and action, to move unfamiliar events or bizarre cultural entities close to bodily experiences and phenomenological certainties, and to establish internal relationships between human and non-human beings, government and family, political structure and natural elements, and so on. (Descola, 2005). Thus grounded in the experiential bearings proper to the human mind, culture is not only the correlate of the counterintuitive, evocative, relatively free work of the imagination through which culture bearers distance themselves from the here-and-now imperative

\footnotetext{
${ }^{2}$ The divide we presuppose between mind and culture can be seen as artificial (or even absurd) to those who insist on the role of culture in shaping cognition (Vygotski, Cole, etc.). Without completely denying this cultural ascendancy (see our conclusion, for example), we will retain this dichotomy for the sake of the argument. One of the main heuristic advantages of this position is that it does not postulate $a$ priori that «culture changes everything». By avoiding the isolation of the mankind from all other species (and of the social sciences from all other sciences), it facilitates the exploration of continuity between non-human and human minds.

${ }^{3}$ There is still controversy about primates' capacity for analogy-making. For D.Premack D. \& A. Premack (2002), primates have the ability to judge the likeness of objects or rather the likeness of the mental representations of objects; monkeys, however, fail in conceptual matching tasks.
} 
and requirements. It is also the correlate of the endless work of analogymaking that holds culture together by creating intuitive rather than counterintuitive connections between a priori separate ontological domains ${ }^{4}$. But before developing this hypothesis, we have to show first how social forms, and the set of expectancies that goes with them, might constitute the natural backbone of culture.

\section{Social forms as ontological primitives}

Compared with "brute" facts such as mountains or molecules, cultural entities are often considered disembodied and abstract, if not ghostly beings, which are suspended in the semiotic webs of significance human beings themselves have spun (Geertz, 1973). Obviously this ghost-like status does not satisfy the naturalist requirements for ontology. These requirements might be satisfied only if an ontological "missing link" is established between individual organisms and collective symbolic representations ${ }^{5}$. To us, this missing link does not consist of mental states and physical objects, that is, the entities accepted by naturalists until now, but of the social and nevertheless natural facts from which most cultural facts stem. Actually, natural entities or properties are not necessarily the physical entities or properties picked out by the laws of physical sciences; they also can be the universal social forms that characterize primary forms of life, themselves coupled with domain-specific cognitive mechanisms of attention and action: basic relational "formats" (cooperation, dominance, kinship, competition) (Cheney \& Seyfarth, 1990, Cosmides et al., 2003), patterns of actions (fighting, sharing, reconciling, playing) (de Waal \& Filippo, 1996), situations (food gathering, political struggles) (Kaufmann \& Clément, 2003), and even obligations and prescriptive rules (Flack et al., 2004). These inductively rich social forms, easily graspable for competent beings, make others' behavior highly predictable and turn the social world into an orderly place. The salience of group coalitions, for instance, enables individuals to avoid the cost of unpredictable interactions with strangers and to maintain relatively low-cost coordination with relevant nearby conspecifics (Kurzban et al., 2001; Gil-White, 2001). Given the intuitive relevance of those coalitional alliances, they have most likely facilitated the creation of cultural constructs based on group membership, such as ethnic groups, casts, local communities or nations. Such derivation from society to culture can also be found in religion if we follow Durkheim's assumption, according to which God is a moral transfiguration of the influence that society exerts on its members (Durkheim, 1991, p. 391). In other words, culture can be seen as the high-level semantic elaboration and redescription of elementary social facts, which are, so to speak, its natural, universal substrate.

Admitting universal social regularities or organizational "objects" to a naturalistic ontology calls into question the widespread idea that psychological states are the only ontological bridge between natural facts and cultural phe-

\footnotetext{
${ }^{4}$ The importance of analogy is highlighted in contemporary anthropology too, as demonstrated by Philippe Descola in his important book, Par-delà nature et culturel (2005). He notably points out that analogical thinking can be seen as a cognitive basis for collective representations (p. 159).

${ }^{5}$ It is probably worth stating again that this separation between individual subjects and societal representations is more logical than empirical. The purpose of such a theoretical reconstruction is to identify the different levels of capacities that enable the emergence of human culture. Of course, once cultures are embodied in human communities, it is absurd to imagine any empirical person existing before or independently of the norms and values of her group.
} 
nomena and hence that naturalism can be nothing but materialist and mentalist. On one hand, although those social forms are not, strictly speaking, material facts, they might deserve the ontological status that is usually intended for brute facts because they have objective, external and potentially causal proper$\operatorname{ties}^{6}$. On the other hand, social forms do not need to win their autonomy over psychological processes for the simple reason they are not, strictly speaking, the product of individual actions and decisions; they are based on the ecological laws of cooperation, subordination, competition and rivalry. In other words, the ontological status of social forms can be compared, at least to some extent, with that of colors as described by Lakoff and Johnson (1999, p. 25). Indeed, colors are neither objective facts in the world, nor subjective sensations in our head because they are "interactional": just as there is not some blueness in the sky independent of retinas, there are not social relationships out there in the environment independent of the competent eye of their beholders. The grasp of social forms indeed depends on appropriate mechanisms of perception and recognition, mainly gaze following, emotion and intentionality detection, and action monitoring (Baron-Cohen, 1995; Conein, 2005). But social forms, even if their qualities as we can experience and comprehend them depend crucially on our cognitive makeup, are as natural as colors. They are part of the sensorymotor world of both vertical (dominance) and horizontal (affiliative) relationships that hold among group members and that primates share with human beings (Tomasello \& Rakoczy, this volume; Tomasello, 1999). In other words, social forms, which are, so to speak, the organizational units parsing the social totality, can be seen as affordances.

\section{Social affordances}

Affordances are the opportunities for perception and action offered by the environment to an organism, whether human or not, such as graspability, "siton-ability" and so on. According to Gibson's theory, affordances are relational properties; they are neither in the environment nor in the perceiver, but are derived from the ecological relationship between the perceiver and the perceived so that the perceiver and perceived are logically interdependent (Gibson 1979, Stavros Valenti \& Gold 1991, Good 2007). Affordances emerge from the coupling between the behavioral and cognitive capacities of a given organism and the objective properties of its environment. This coupling is grounded in the long-term attunement proper to evolution: given the needs of a particular species, its hard wiring can be contended to have evolved in a direction that simplifies picking up the necessary information and parsing the environment in a specific way (Sanders, 1997). But this coupling is also grounded in the shortterm attunement proper to situated action: the structure of material objects but also of social relationships can be said to create additional environmental properties that constrain an additional set of actions, for instance the "weaponability" of a branch or the relationship-solidifying function of a gift (Schmidt, 2007). In both cases, the perceptual system of fine-tuned organisms resonates with the properties of their environment, which is essentially a field of practice, a "taskcape" (Ingold, 2001).

Along the same lines as Gibson's, our hypothesis is that the richest and most elaborate environmental affordances are provided by other animals and other people (Kaufmann \& Clément, 2003). "Sexual behavior, nurturing

\footnotetext{
${ }^{6}$ On the ontological distinction between brute and institutional facts, see Searle (1995)
} 
behavior, fighting behavior, cooperative behavior, economic behavior, political behavior - all depend on the perceiving of what another person or other persons afford, or sometimes on the misperceiving of it" (Gibson, 1979, p. 135). Between the affordances for physical interactions with the environment (grasping, eating, walking, etc.) and the culturally determined affordances that reflect preferred but not necessary interactions (i.e. hat affords wearing on one's head), there might be affordances for social interactions: aggressive behavior affords defensive reaction, a gift affords cooperation and kin in distress affords help. By analogy to the "demand character" of objects that Koffka (1935) speaks of, for instance the post-box inviting the mailing of a letter, we thus suggest that social objects have also a "demand character": typical social situations, relationships and actions trigger specific kinds of reactions and structure how to behave toward others and what to expect from them. As Véronique Servais (this volume) interestingly emphasizes, in line with Bateson (1963), social signals are two-sided entities; they are at the same time a report (on a past event) and a command or a stimulus (for a behavior). For example, she says, it is the "command" aspect of the baby-like features of a kitten that "tells" us "take it in your arms". To us, this "command" aspect, which has the ability to create standard chains of social interactions and relationships, is made recognizable thanks to the selective attention to facial expressions, sounds, body postures and direction of gaze, whose meaning can be seen as "natural", in Grice's sense (1957). Just as smoke meaning fire is a matter of smoke being reliably connected with fire, facial expressions such as fear are reliably connected with the action of fleeing and gaze direction reliably indicates the attention to something salient or interesting. Unlike the comprehension of "non-natural meanings", which implies the use of conventional symbols and the reconstitution of intentions, the recognition of the natural meaning of social affordances and the appropriate reaction to it are quasi-immediate. Just as evolved social animals have developed a visual system that enables them to extract lawfully generated patterns in ambient light, they would have thus developed a quasi-perceptual system of capacities that would allow them to detect social affordances?. This is the specific evolved system of social capacities, suggested by Jackendoff (1992) and named by Hirschfeld (1995, 1996), that we call "naïve sociology". Naïve sociology would be a phylogenetical adaptation for picking up the elementary social gestalts or patterns that are important to the fulfilment of survival and cooperation needs.

\footnotetext{
${ }^{7}$ By using here the notion of «quasi-perceptual», we want to insist on the inferential work involved in visual cognition while keeping Gibson's idea that an important part of the information needed to make sense of the world is «out there», in the external environment. Perception, defined as the «processes by which we organize and interpret information about the world that has been collected by our sensory receptors ", is a complex process. It notably requires time (it is not direct), memory (recognizing something as a bird or a book requires the recollection of past representations which go, by definition, beyond the information given), and is context-sensitive (Pomerantz, 2003). It would thus be misleading to think of perception as deprived of the internal, complex treatment that characterizes other kinds of cognitive processing because the difference between perception and more inferential cognitive processes is more a matter of degree than a matter of kind. Therefore, while taking up the concept of affordance and its insightful emphasis on the contribution of external structures to perception and action, we do not believe in the strong perceptive/cognitive partition that can be found in ecological psychology. Perception is a kind of «visual cognition», even if it requires inferential work that is less demanding than that of action planning or discursive production.
} 
Of course, the hypothesis of natural social gestalts, both shaping and being shaped by naïve sociology, cannot avoid one of the main issues raised by physical affordances in ecological psychology, namely whether the impersonal, objective status of affordances is culture-independent and hence whether direct perception is pre-social and universal (Costall, 1995) ${ }^{8}$. Does the demand or command character of a given thing vary according to the perceiver's needs or cultural background, or does it remain, on the contrary, invariant? Different scholars insightfully suggest that there might be a "natural semiosis" (Rosenthal \& Visetti, 2003) or a "primitive semiosis" (Quéré, 2001) that preorganizes the environment and segments the flow of socio-cultural activities into perception-based, observable and categorizable entities. According to Quéré (1999), however, the primitive semiosis permitting the preconceptual perception of the milieu is mediatized by the abilities, habits, rules and institutions peculiar to a given community of language and practice. By contrast, the natural, social wholes that we hypothesize here are not dependent of cultural, rule-governed situations, customary practices or conventional meanings. Rather, they are social regularities that have elicited, over phylogeny and ontogeny, the development of capacities for the individuation of relevant units of action or relationship and the recognition of those very units as the occurrences of a given type. To us, the detection of physical and temporal regularities in the behavior stream is grounded in a "seeing-as" that is not culture-dependent as such, that is, not fostered by institutional constraints, established at the end of rational discussion or created by collective intentionality. This being so, if social affordances are not culturally relative, but depend on the needs and capabilities for action of social evolved animals, they differ in an important respect from the traditional physical affordances. These latter bring into play the instantaneity of a Gestaltist direct perception, which is said to be free from inferences and cognitive processing (Turvey et al., 1981, Reed 1996). In contrast, the "seeing-as" of universal social affordances that we hypothesize involves a proto-"counting-as", namely an inference-based action parsing that counts a certain event as the instantiation of a typical course of action. As such, the detection of social affordances is not inference-free; it involves a range of expectations, generalizations and predictions that go beyond the information "contained" in the external environment. When "seeing", for example, two individuals engaged in a hostile relationship at the time tn, we expect that they will not share food at the time $t n+1$. This kind of prediction, whose status is in between perceptual (e.g. they are anchored in perceptual cues) and theoretical processing (e.g. they go beyond immediate informational array), enables social beings to anticipate the outcomes of typical situations.

\section{The emergence of cultural norms}

Given their intermediate status, half-inferential, half-perceptual, social affordances are not synonymous with mere factual, statistical frequency; on the contrary, the social normality of primitive forms of coordination can become

\footnotetext{
${ }^{8}$ Here again, the issue of the universality or cultural-dependency of social affordances is close to the debate about color processing within and across cultures. Actually, recent works emphasize the interaction between the perceptual saliencies of basic color categories, which would be common to all human beings, and the linguistic or cultural salience of color-naming. Cf. the volume of Journal of Cognition and Culture, vol 5, no 3, 2005 dedicated to this debate, and more particularly, the afterword of Don Dedrick «Color, Color Terms, Categorization, Cognition, Culture: An Afterword», pp.487-495
} 
normative, even in primate societies. To some primatologists, indeed, a major part of behavior regulation in primates and chimpanzees can be accounted for in terms of social rules, either descriptive or prescriptive, and judgments of rule compliance (Flack et al., 2004)9. To de Waal (1991), "descriptive rules", which are typical responses to a specific social situation - such as when females with young respond with either withdrawal or aggression to conspecifics threatening their offspring - must be distinguished from "prescriptive rules". Descriptive rules refer to statistical regularities in social interaction patterns; by contrast, prescriptive rules in male sexual competition, food resources and juvenile care do imply a reinforced sense of how others should or should not behave as well as the anticipation of the consequences to one's self of deviating from that regularity. The maintenance of the "order without law" that defines primate societies (Goodall, 1983) requires a certain level of cognitive complexity, from the parsing abilities to access appropriate units within social continuous behaviors to the expectations about the way in which oneself or others should be treated.

The existence of non-institutional social rules in non-human primate societies and the cognitive complexity of their processing give an interesting insight into the phylogeny of human, culture-specific norms. Generally, human norms are believed to be the mere product of collective choice (Searle 1995) or arbitrary power (Foucault, 1971), that is, the result of an "instituting" moment whose main function would be to widen the gap between nature and culture. Most of the evolutionist views of norms consider the capacity for reading other minds, evolved in the Machiavellian race for social skills and deception, as their starting point: both norm compliance and prediction would involve the metarepresentational ability to hold in mind simultaneously what people, oneself included, are doing and what they are supposed to do (Byrne \& Whiten, 1988). The embedding of cultural norms in natural social regularities suggests an alternative model that is probably complementary. In the continuist model of nature and culture we would like to propose here, indeed, cultural norms do not have necessarily intentional or mentalist origins. They can emerge from the phylogenetic and ontogenetic readiness of well-adapted beings to learn and use social forms and regularities as a basis for inference and action, which ends up loading them with a normative weight.

Interestingly, this process of self-reinforcement and normativisation of preexisting social regularity or normality is close to the model of conventions that Lewis $(1969,1993)$ speaks of, once this model is cut off from its individualistic tendency. In fact, the economy of conventions might avoid one of the main issues raised by the naturalistic approaches that account for the genesis of rules in terms of collective agreement, mental representations or decision-making. The issue in question is the fact that, logically speaking, a collective agreement cannot be reached without the prior existence of shared rules making this very agreement or decision possible, thereby putting back ad infinitum the moment of the decisive creation of human-like norms. This infinite regress of rule-

\footnotetext{
${ }^{9}$ According to recent findings by Flack et al. (2004), older and younger juvenile chimpanzees engaged in play can appropriately regulate their behavior, including their own play signaling, to avoid interruptions by nearby adults who might be monitoring the interaction. This fine-tuning of the signals, aiming to preempt the anticipated behavior of protective outsiders, e.g. the termination of the play, shows the juveniles' perception of «the prescriptive social rule» regulating the expected intensity and noise of play.
} 
based stages does not hang over the theory of conventions because conventions are behavioral regularities that function practically as tacit norms - not because of their intrinsic quality but in virtue of the coordination of actions they permit. Far from any explicit, contractual consent, conventions emerge from the mutual and convergent expectations of the normal behavior that everyone is presumed to adopt (Lewis, 1969; Dupuy, 1989; Quéré, 1993). The common bearings of coordination are the publicly manifest, objective and impersonal regularities of behaviors to which any competent social being tends, and is supposed, to conform. Seen from the angle of conventions, social conformity does not derive from rule or norm compliance but from the recognition of a new situation as being analogous to previous situations (Lewis, 1969, p. 42). The self-perpetuation and stabilization of expectations and actions that turned out to be effective and relevant in the past, including in the distant past of ancestral forms of life, are sufficient for action coordination to take place.

The economy of conventions gives us useful hints about how human beings might derive social rules from social regularities without the mediation of subjective interpretations or explicit agreements. Thanks to the normativity of conventions, which derives ex post from conformity expectations and predictions, the gap between the factual "is" of social regularities and the normative "ought" of cultural norms can be bridged without resorting to a primitive scene of agreement-making and linguistic creation. Within the conventional scenario, indeed, language does not constitute cultural norms from scratch by assigning them a deontic function (Searle, 1996); it just redescribes and then confirms a preexistent set of well-established practices under an explicitly normative format. Admittedly, in primate societies, this prescriptive dimension takes the form of a logical "must" rather than the form of a normative "ought to". For instance, anyone who means to play must comply with the nonaggression pact that constitutes by definition the act of playing; if not, he or she is no longer playing but is instead instantiating another rule of action, like fighting. The most primitive modality of prescriptive rules consists of an if-then pattern - if you play, then you do not bite "for real"; it can also consist of a chain of "action-reaction" - if you are groomed, then you reciprocate. This kind of constitutive rule enables social beings to anticipate the fact that each time A occurs, B will appropriately follow; and that whenever B occurs, it will have been preceded by A (Duncan \& Farley, 1990). But even in this weak, quasilogical sense of rules, the naturalist continuum we want to defend here is maintained: the social "is" or "must" can turn into an "ought", that is, into cultural normativity, without necessarily making the symbolic leap from nature to culture that language and mind reading are said to trigger. From both ontogenetic and phylogenetic perspectives, a part of cultural norms and symbols might remain closely related to the tangible, quasi-perceptible world of social forms and regularities. As Peter Goldie put it (2007), even if normative demands on action are not strictly speaking perceptually manifest in the way that colors, shapes - and, in our case, social affordances - are, they are immediately recognizable: they allow socially competent individuals to see what is the right, appropriate thing to do in any given circumstances.

\section{The intuitive share of culture}

The integration of descriptive, natural social rules and normative, cultural norms into a continuum built upon elementary, invariant social configurations that have rudimentary counterparts in the animal world does justice to the insistence of social anthropology on the organizational aspects of socio-cultural 
phenomena. We have hypothesized that a part of cultural norms, that is, culturally transmitted representations and values specifying which behaviors are socially commendable or punishable, appropriate or irrelevant, good or bad, emerged from universal social regularities. However, if the impersonal, potentially universal organization of social interactions can be seen as the mark of the social, it does not constitute the mark of the cultural, whose study has been traditionally entrusted to cultural anthropologists. In fact, our continuist hypothesis sheds light on the emergence of cultural norms. Far from being created from scratch by human minds, the latter might be high-level semantic redescriptions and reconfigurations of pre-existent social regularities and can be assumed, as such, to be artificial without necessarily being arbitrary. But this continuist hypothesis does not yet account for the mythological, religious, and political constructs whose arbitrariness is said to be one essential feature. As pointed out by numerous scholars, the mark of the cultural is the diversity and relativity of the domains of constructs that furnish the human world, such as religion, art, ritual, ideology, and language. Indeed, "humans inhabit a world in which promises are explicitly made, contracts symbolically formulated, taboos laid down for ritual observance, often on pain of 'supernatural' punishment" (Dunbar et al., 1999, p. 5). To pursue the same continuist line of reasoning as for social forms and cultural norms, we have to see whether symbolically constituted constructs might have intuitive features, what would enhance their chances of being salient to human minds.

To us, symbolic constructs are indeed endowed with intuitive features thanks to the cognitive device, namely analogy-making, which projects upon them intuitive expectations drawn from domain-specific knowledge and ordinary experience. Yet, at first sight, analogical cross-domain mappings between existing structures seem to create mysterious connections rather than intuitive meanings, as revealed by the well-known analogical puzzles that anthropologists are used to encountering in the field: "twins are birds" (Evans-Pritchard, 1956), "we are parrots" (Crocker, 1977), or "leopards are Christians" (Sperber, 1975). This kind of puzzle raised such enduring perplexity in external observers that it triggered the counterintuitive explanation mentioned above. This is the violation of intuitive knowledge and ontological assumptions that renders the analogical strands in culture attention-arresting, evocative and emotionally provocative. By provoking intellectual surprise and awe, crossdomain analogies enhance their probability of being replicated and entertained by human minds (Sperber, 1996; Boyer, 1994).

The definition of culture as a set of catchy, half-understood, and juxtaposed representations, defined by their counter-intuitiveness, is very interesting. First, it succeeds in locating the essential part of culture in the mental structure of the minds it causally emerges from and will be realized in (Atran et al., 2005). Second, this counterintuitive definition of culture rightly contests the view of culture as a latent variable that suffuses all aspects of belief, intention, and collective life (for an excellent review, see Di Maggio, 1997). Third, it succeeds in releasing - at last - ordinary agents from the cultural blindness that used to turn ordinary people into "judgmental dopes". But the cost of this triple success is heavy since such a model tends to eliminate two essential characteristics of culture. From an ontological point of view, it assumes that the interrelations weaving together different kinds of reality in the conjunctive fabric of cultural cross-references can be pulled apart and articulated in a set of individuated, labelled representations. While fending off the hypothesis of 
cultural symbolism as a language with coded, defined meanings, the counterintuitive model thus retains taking the propositional format as main paradigm. Culture is seen as a set of causally related distant propositions or semipropositions, whose variously patterned distributions within and between human populations are assumed to be the ultimate unit of cultural analysis. From a cognitive point of view, the counterintuitive model assumes a one-way dependency that gives absolute priority to domain-specific processing of reality over faraway cultural interpretations and evocations. Once their epidemiological success is ensured by their attention-arresting, memorable properties, cultural representations are endowed with a specific cognitive status: they are bracketed between circumspect "quotation marks", which prevent their direct implication in the inferences and actions linked to the tangible, indubitable reality of the natural world (Sperber, 1975). In postulating an impervious cognitive barrier between basic-level, concrete primary domains of experience and abstract, secondary cultural constructions, this model posits both individual and collective clear-headedness as for the situated and "forevocation-only" status of culture (Sperber, 1996).

The problem is that this conception, pushed to an extreme degree, suggests that culture, ideology, and religion are mere epiphenomena: individuals owe to the nature of their brains the innate ability to keep their distance from the cultural world around them. By restricting counterintuitive analogies to a culturebound system of knowledge kept apart from the intuitive, reality-based system of knowledge that organizes experience, this view leaves aside the issue of the ontological commitments that culture can foster, mainly via the naturalization of ideological meaning $s^{10}$. Moreover, the counterintuitive view does not take into consideration the fact that the cultural world has analogical mappings at its disposal to enter the supposedly impenetrable cognitive basis for inference and action. Analogical predications draw relational commonalities that are more intuitive than counterintuitive. As will be seen, this intuitiveness is not only due to the "anchoring" of analogies in sensorimotor experiences and phenomenological certainties that constitute, if we follow Lakoff and Johnson (1980, 1999), the "hidden hand" of cultural understanding. It is also due to the political art that consists of turning arbitrary cultural elaborations into taken-forgranted, deferential representations. This is the intuitive part of culture, either resulting from a "bottom-up", experience-based process of "reappropriation" or a "top-down", ideological process of embodiment, that the next and final part will consider.

\section{CULTURE AND THE ANALOGICAL MIND}

\section{Two main modes of information processing}

For a long time, anthropologists had a tendency to distinguish between two main kinds of thought, whether rational and symbolic, logical and participative, or engineer- and handyman-like. Although this condescending approach, which led to a phylogenetical and ontogenetical hierarchy between primitive

\footnotetext{
${ }^{10}$ Naturalization has two senses that make this term ambiguous and interesting. In the social sciences, naturalization refers to the process of making arbitrary, culture-made institutions look natural, timeless and definitive. In cognitive science, it refers to the assumption that human beings are the evolved products of natural selection and are, as such, shaped by the various processes - physical, biological, psychological - that science describes. We will return to the polysemy of the term «naturalization» in our conclusion.
} 
and elaborated modes of thinking, has been abandoned, contemporary cognitive science is far from invalidating the existence of different types of cognitive mechanisms. Nowadays, cognitive and developmental psychologies tend to discriminate between two main modes of reasoning and understanding, namely the causal and the analogical ${ }^{11}$. These two "cognitive subspecies" are high-level modes of information processing, both organizing in their own way the perceptual and low-level conceptual knowledge provided by the modular, foundational treatment of inputs ${ }^{12}$. Both modes of reasoning are thus rooted in the same universal abilities that allow human beings, if not primates, to extract a significant "surplus" of information from the episodic and fragmentary data provided by their environment. Although present too early in the development to involve explicit meta-representational ability, which is cognitively too "heavy" for young children, analogical and causal thinking probably involve a tacit, fundamental meta-representational capacity, either for detecting relations between objects (causality) or relations between the relations between objects (analogy). For Goswami (2001), both modes of thought show the primacy of "relational processing", either based upon attributes of objects (solid, round) or upon relations (push, collide).

However, causal and analogical relational ways to "comprehend" information that would be otherwise scattered and muddled are different in many respects. Causal thinking draws an external connection between a priori separated entities, for instance a billiard ball bumping into another one. The identification of the causal link connecting the antecedent event with the consequent event, in this case the impact of the first ball and the movement of the second ball allows us to explain and predict their respective behavior. The detection of causal links thus enables us to reach understanding via an explanation, whether mechanist, functional, intentional or essentialist, which is fundamentally sequential. The explanation consists of integrating into a temporal order of succession the events brought about by the intervention of individuated, external entities - whether this intervention is contingent (the encounter of billiard balls) or law-like (the sun causes the photosynthesis of plants).

Unlike causal thinking, analogical thinking does not apply to entities but to relational patterns that make an obscure phenomenon intelligible by relating it to a familiar, comprehensible one (Gentner et al., 2001c). Analogical mapping plays a crucial role in understanding (also in scientific disciplines) because it enables to transfer a relational property from a well known "source domain" to a largely unknown "target domain". For example, the flow of people in a crowded subway can be compared to the flow of electrons in an electrical circuit, what leads to the following relational matching: "the resistor decreases the flow of electricity as a narrow gate decreases the flow of people" (Gentner et al., 2001a). The key similarities lie in the relations that hold within domains rather than in intrinsic features of individual objects; electrons are not like people, even though the flow of electrons is analogically similar to the flow of

\footnotetext{
${ }^{11}$ The issue of which labels would be more appropriate to those two kinds of reasoning remains a controversial topic. If we follow Tanguay (1984) for instance, neuro-psychologists distinguish two forms of cognitive processing, the "holistic" and the "sequential" modes of thought.

${ }^{12}$ This being so, it seems that analogy-making and causal detection do not occur at exactly the same level of the cognitive architecture. In fact, analogical mappings are based on relations between relations whereas causal relations are drawn between objects.
} 
people. Similarly, the analogy "Mind is a Computer" requires a structural alignment from the domains it relates, that is, the mental world and the computational operations, such as information processing, encoding, feedback and memory stores, which characterize artificial intelligence. Far from being sequential, analogical thinking can be seen as "holistic" or structural: it picks out patterns, identifies recurrences of these patterns despite variation in the elements that compose them and forms concepts or symbols that abstract and reify the patterns in question. Analogical thinking, therefore enables us to recognize the similarity of relations between forms (two triangles are similar to two circles), situations (the groom veils his bride's face like the lioness covers her brood) or roles (the relation of "marriage" between "husband" and "wife" are distinct from the particular fillers of the role, e.g. John and Mary) (Gentner, $2001 \mathrm{~b})^{13}$. Evidence for the precocious development of such relational processing, fully acquired at the age of 4 , is the fact that infants are able to draw an analogy between visual inputs (an arrow pointing downward or upward) and acoustic inputs (ascending tone of music) (Wagner and al., 1981), to connect their own felt but unseen movements with the seen but unfelt movements of others (Meltzoff \& Brooks, 2001), and to empathize with other's emotional states (Barnes \& Thagard, 1997) ${ }^{14}$.

For certain scholars, analogical reasoning is so central that it is not just one way of thinking among others but the very core of cognition. According to Hofstadter (2001), for instance, every concept is a packaged bundle of analogies because it involves a mental matching, necessarily approximate, between single words and perceived situations, prior categories and new things, or old memories and novel occurrences. Although this overextension of analogical processing tends to wrongly suppress some important differences between sequential and holistic thinking, it does emphasize an important point: far from being confined to scientific laboratories and problem-solving tasks psychologists have insisted on, analogy-making plays a key role in everyday life. It also plays a key role in the incredible symbolic profusion that characterizes culture.

\section{Cultural analogies}

Drawing relational matching across diverse conceptual domains and integrating them into new generative blends is a very powerful natural ability. It helps individuals to go beyond what they directly encounter and to look for common patterns in different domains of knowledge and experience. This piece-together patterning can be seen as the essence of culture in the symbolically constituted sense of cultural anthropology. It is an essential element of the "tool kit" or the "prosthetic devices", as Bruner (1990, p. 21) put it, by which human beings can exceed or even redefine the natural limits of human functioning in order to make sense of the world they live in. By contrast with the universality of social affordances, the conceptual commonalities created by analogical patterning are culture-specific. As such, they are only graspable by

\footnotetext{
13 As Gentner and al. (2001b, p. 241) put it, those analogies derive their force not from a local resemblance between physical objects and memory traces but rather from mapping the system of relationships in which these objects are embedded.

${ }^{14}$ As with the motor analogies that Piaget pointed out, infants compute the relations between organs, such as tongue-to-lips, and use these to represent both their own behavior and that of the adult. The perceived organ thus provides the target that the infant attempts to match, which requires from her the recognition of the structural equivalence between another agent's behavior and her own (Meltzoff, 1990).
} 
competent natives or, perhaps, by an ethnographer "experience-near" enough to reconstruct not what natives effortlessly perceive, which is impossible, but what they perceive "with" - or "by means of", or "through" (Geertz, 1975). For an outsider, the reconstruction of this culture-specific perception is all the more difficult because cultural analogies, unlike scientific analogies, rarely consist of a "one-way" explicit alignment from the representational elements of a known source domain to that of an unknown target domain. Similar in this respect to literary metaphors, cultural analogies are characterized by a cascade of crossweaving connections that make it very difficult to recognize any one-to-one correspondences.

This is precisely the difficulty in accounting for the conceptual path that underpins cultural analogies which struck the anthropologist Lawrence Hirschfeld in his fieldwork in Sumatra (Hirschfeld, 2000). Very impressed with Toba Batak aesthetic productions, he asked the locals about the meaning of carved stylized lions on each house and was offered an explanation in terms of indirect kinship exchange. Despite seeing an obvious connection between these architectural pieces of art and "the social mechanics of matrilateral crosscousin marriage", the Toba were not able to explain this connection to the perplexed anthropologist (Hirschfeld, 2000). Hirschfeld hypothesizes that this connection did remain mysterious to the Toba, in the sense of not being fully interpretable, because kinship was "what Toba monumental architecture was about but not what it meant". In other words, analogical mapping between kinship and aesthetic production was stipulated rather than inferred from mapped relations, which leads Hirschfeld to favor a counterintuitive thesis. These mysterious analogies would be the sort of terminally uninterpretable representations that Sperber (1996) sees as being catchy candidates for stable and widely distributed cultural representations.

And yet the analogical mapping between kinship and aesthetic production, although mysterious and unexplained to the anthropologist, is not necessarily meaningless or beyond the cognitive grasp of natives. Analogical predications might well be pregnant with felt but unconceptualized meanings that come closer to a "seeing as" embedded in a worldview than to a "seeing that" easily translatable into some isolated assertion of similarity, either propositional or semi-propositional. As Davidson (1978) put it, what analogies make us notice is not finite in scope and propositional in nature; they do not have an encoded cognitive content, a conveyed message that interpreters must identify ${ }^{15}$. Analogies provide competent perceivers with a kind of lens or lattice enabling them to perceive relevant resemblances without actually saying or hiding them. Actually, Davidson says, when analogies make us notice a figure like a duck instead of a rabbit, there are no propositions expressing how it led us to see that. For analogies belong exclusively to the domain of use: they are brought off by our imaginative, context-dependent employment of words and concepts, which allows one thing to remind us of another ${ }^{16}$.

\footnotetext{
${ }^{15}$ We have chosen to apply to analogy what Davidson says about metaphor to the extent that the basic processes of analogies are also at work in metaphor, namely structural alignment, inference projection, progressive abstraction, and re-presentation (Gentner et al., 2001a).

${ }^{16}$ Counter to the dual stage hypothesis, which asserts that people first attempt to process literally a meaning and, when they fail, try to process it non-literally (Searle, 1976, Sperber, 1975), this pragmatic view sees the analogical meanings people are familiar with as a kind of polysemy that is spontaneously enacted when the context is favorable.
} 
From this perspective, it is no wonder that semantic inquiry and the propositional account are not suitable for analogies, particularly if they belong to extended cultural systems such as the Toba Batak one. The "lion-kinship" mapping might indeed be a frozen, dead or latent analogy of which users are no longer aware - a mapping that became conventionalized to the point that its metaphoricity was forgotten (like the analogical mapping according to which a minister was a small man as opposed to a magister, a big man). (Johnson, 1981; Miller, 1979). Once conventionalized, latent analogies become part of the mostly unconscious cultural frame that prompts intuitive insights and directs attention to some salient properties over others. Tracking down the likeness that the mapped elements and hence the original domains bear to one another might therefore be hopeless. For cultural analogies are less the product of a one-way structural alignment between source and target domains than the elaboration of a new "meta-domain", an imaginative blend which develops an emergent organization of its own (T. Turner, 1991; Fauconnier, 1997, Fauconnier \& M. Turner, 1998). In other words, analogical mapping creates a "new mental assembly", a conceptual blend, which triggers a specific set of inferences, solutions and actions (M. Turner, 2001). A creative blend like "Man is Wolf to Man", for instance, draws on the ferocity of the wolf to highlight a largely unknown target domain - human nature - and ends up reified in an institution such as wolf-like competition in the free market. Once integrated into a new blend, the contributing domains of the blend (e.g. "man" and "wolf") do not remain intact; on the contrary, they are restructured by continual revision and backtracking (i.e. the man becomes more "wolfy" and the wolf more human) (Black, 1955).

\section{The participative stance}

Unlike most scientific analogies, for instance "flow of electrons - flow of people", cultural analogies generate a blending, that is, an invisible conceptual meta-domain that rules the cross-domain alignment between A and B (e.g. architecture/kinship, wolf/man, etc.) and therefore fosters culture bearers to think of $\mathrm{A}$ as $\mathrm{B}^{17}$. If neither natives nor anthropologists are able to reconstitute the original domains of a given cultural blend, for instance the well-known "Twins are Birds" of the Nuer, it is because the blend functions as a triadic rule and transforms both terms of the analogical mapping, in this case twins and birds, into the instantiations of a third, higher order (Evans-Pritschard, 1956; Fernandez, 1977). Statements such as "twins are birds" are made in relation to a third term: "They are statements, as far as the Nuer are concerned, not that A is B but that A and B have something in common in relation to C" (EvansPritchard, 1956, p.142). The latent generic characteristic that associates twins and birds is spirit: twins, like birds, occupy an intermediary position between supreme spirit and human beings. To recognize this position as the common, and supposedly preexistent, concept justifying the enrolment of twins and birds in the same symbolic blend, individuals must reach a higher level of abstrac-

\footnotetext{
${ }^{17}$ Although analogical thinking is grounded on a unique cognitive operation, the production of cultural analogies is less constrained and rigorous than scientific analogies. In theory indeed, analogical alignment follows three main steps: the «mapping step», which consists of finding one-to-one correspondences, based on the sameness of relations, between the source and the target domain, the «inference step», whose main task is drawing goal-relevant inferences, and the «learning step», which consists of abstracting more general commonalities between the domains at stake (Holyoak \& Thagard, 1997). Clearly, cultural alignments do not follow these three steps systematically.
} 
tion that frees them from a preoccupation with the contributing parts of the blend in question and enables them to get to the whole (T. Turner, 1991). The distinction between source domain and target domain does lose relevance in the organized blending and structural homologies that constitute culture as a symbolic totality.

Far from being autonomous, isolated building blocks of culture, therefore, analogical mappings have a metonymic dimension: they hold for the cultural totality in which members can participate only by a stretch of the imagination. To enter the totality constituted by cultural commonalities, individuals have, indeed, to adopt a participative stance that allows them to go beyond their own narrow sphere of experience and thereby to reach the sphere of the collective imagination ${ }^{18}$. In other words, cultural bearers have to give up both on the fictional stance devoted to invisible, anomalous entities (e.g. Santa Claus, the Tooth Fairy) and on the empirical stance devoted to creatures that exist and can be seen, either directly or by means of a veridical representation such as a photograph or film (e.g., wolves, tigers) (Harris et al., this volume). They have to adopt instead a participative stance that requires a deferential attitude towards the strange entities and analogical blends furnishing their world ${ }^{19}$. By enabling the grasp of collective constructs, cultural analogies included, this deferential attitude plays an important role in the symbolic and social integration of community members. Symbolic integration because they foster the diffuse feeling that all beings and orders separated in everyday life have become the interdependent parts of a unique totality, suffused with meaning ${ }^{20}$. When enacted in specific cultural contexts, the relation of representation that ordinarily underlies analogical predications turns into a relation of ontological equivalence: instead of representing birds, twins are birds for they belong with

\footnotetext{
${ }^{18}$ Of course, the term «participative» alludes to Lévy-Bruhl's work on the mystical experience, enhanced by collective ceremonies, which allows community members to access the invisible part of the whole social structure. After attributing the indifference to the law of contradiction only to the «primitive mind», Lévy-Bruhl (1938) extended it to any kind of mystical experience. Having entered a nonsensible, invisible world, community members can hold two contradictory beliefs, one ordinary, the other social, because they replace momentarily the «principle of non-contradiction» with the «law of participation» permitting, for instance, the dead to be a corpse and a spirit at the same time.

${ }^{19}$ The issue of deference can not be dealt with in this paper but it has an important role to play in the transformation of a priori anomalous blendings into endorsed, obvious matchings. In fact, ordinary agents defer to a competent authority, whether it be the collectivity as a whole or the «experts» who represent it, the task of attributing to cultural, a priori empty concepts the referents to which they are not entitled in theory (e.g. the Ancestors' spirits, God, the Virgin, etc.). This validation on credit allows us to distinguish deferential concepts (the Virgin, public opinion) from referential concepts that represent tangible objects (elm, water), as well as from fictional concepts whose use is valid only within a restricted context, isolated from the real world (Frankenstein, Sherlock Holmes). On this matter, see Kaufmann (2006)

${ }^{20}$ Interestingly, Ramachandran and Blakeslee (1999) have shown that mystical feelings are frequent in patients with seizures originating in the temporal lobes. As his patient John put it, «finally I see what it's really about, Doctor. I really understand God. I understand my place in the universe, in the cosmic scheme». Perhaps the important difference between those individual delusions and the collective hallucinations that cultural analogies lead to lies in the «sharedness» of the latter. Otherwise, cultural analogies seem to respond to the same human need, namely the determination of a salient landscape, which highlights what is pragmatically important and emotionally relevant. In strengthening some pathways, cultural analogies progressively deepen the emotional significance of some categories of inputs, imbuing everything, whether a grain of sand, a piece of driftwood, or a birdsong, with deep cosmic significance. See also Bazin (1991).
} 
them in the same order of being. Cultural analogies also facilitate social integration because they integrate scattered individuals into the meaningful cultural totality that all members of the community are part of. Just as political rituals, religious ceremonies, cultural constructs and more specifically cultural analogies work to maintain the "collective effervescence" that Durkheim (1991) speaks of. As Fernandez (1974) put it, one crucial mission of cultural analogies is indeed to transform the pronoun "I" into a "We" that integrates individuals into a "collective mind", whether it be called Spirits, God, Society, or Nation. Interestingly, this twofold function of integration has been recently emphasized by anthropologists interested in the evolutionary origins of culture (Dunbar et al., 1999). Symbolic systems (e.g., rituals, religion, ideologies, or myths) are seen as an adaptative, evolutionary stable strategy to secure integration and cooperation in human social groups and to avoid free riders that would lead society to disintegration. To Dunbar, Knight and Power (1999), following here Durkheim's hypothesis, the cognitive acknowledgment of "contractual intangibles", like spirits, divinities or totems, ensures group-level allegiance and might be, as such, a product of human coalitionary strategies.

It remains to be seen whether the natives' cognitive acknowledgment of the bizarre beings and puzzling analogies that seem to be endorsed in the public discourses and cultural practices of their community is synonymous with a genuine ontological commitment. Given their departure from the actual state of affairs, those publicly endorsed beings should involve one way or another the "willing suspension of disbelief" proper to the "poetic transactions" that Levin (1979: 134) speaks of. But if anomalous beings are said to provoke only a kind of minor, distant, and aesthetic commitment, how are we to explain that those very beings, once culturally loaded, become the essential workings of symbolic and social integration? In fact, it is not difficult to explain since collective constructs do not necessarily require committed, blind beliefs from individuals to operate as cultural glue. The specific kind of belief that certain philosophers like Tuomela (1995) call "positional belief" or "we-mode belief" might be sufficient for their maintenance: "positional belief" is indeed a collective belief that an individual endorses as a community member but does not necessarily endorse as a private person. For instance, natives might "We-believe" in the existence of the ancestors' spirits without privately endorsing the correspondent "I-mode belief". This perspective interestingly allows us to break with a passive conception of culture bearers as blindly swallowing the associations at work in their symbolic environment while emphasizing the creative shift from the ordinary order of things that the grasp of collective commonalities involves. For the reality shift, which allows initiates to enter a culture-specific, mind-dependent order of being in which the boundaries dividing the prosaic world seem to blur, must not be overestimated. It must be all the less overestimated as the "mental leaps", as Holyoak \& Thagard (1995) put it, which enable individuals to go beyond the privacy of the experiential process and the information given to see one thing as if it were another, draw heavily on preexistent concepts and well-known properties. If "the work of the imagination" (Harris, 2000) can turn impossible worlds into culturally possible worlds relatively easily, it is because those very possible worlds are deeply rooted in familiar source domains and sensorimotor experiences. Despite infringing the natural boundaries between the physical, biological, psychological, and social domains they are grounded in, cross-domain analogies do maintain a constitutive link to 
those natural domains - constitutive enough, at least, to make them partly intuitive.

\section{Constituting the cultural order as "natural": Why Bororo men are} Parrots

Emphasizing the intuitive share of analogical mappings returns us to the issue of cognitive and ontological continuity that we are interested in. Despite cutting the world at its cultural joints, generative analogies eclipse neither the ontological domains that carve nature at its joints nor the social affordances that carve the social world. They reinforce and perpetuate the preexistent natural and social saliencies that easily lend themselves to this cultural work of redescription. In fact, nature is such an essential source domain that it can be endowed with a "universal donor status" (Gentner et al., 2001b, p. 242). Analogical mappings drawing from nature have a "relational generativity" (di Sessa, 1983) that makes them cognitively as well as ideologically efficient: by grounding the cultural order in nature, they cement the architecture supporting the edifice of collective beliefs and public "truths". As Mary Douglas (1986) put it, analogical connections between "the formal structure of natural species" and the formal structure of institutions establish the foundational "cognitive conventions" necessary to overcome the sense of contingency and arbitrariness that risks undermining those very institutions at any moment.

In this respect, analogical blending is a very effective ideological device: linking the cultural order to a natural order impervious to human agency and familiar to everybody masks its arbitrary origins. For instance, the analogical mapping "woman is to man what the left hand is to the right hand" conceals political hierarchy behind a supposedly natural complementarity which cuts across different cultural contexts and can serve to justify long-term asymmetries (Douglas, 1986). Analogical cross-references to the movement of planets in the sky and the natural behavior of plants, animals and people contribute to institutionalizing cultural conventions by founding them in nature and then in reason. Once cultural constructs lose their "man-made" appearance and are virtually indistinguishable from the "natural", the idea that human beings created them is an unlikely cognition (Gabennesch, 1990). By grounding institutions in the abstract structure of nature and attributing a natural quality to forces that are essentially human in origin and maintenance, most cultural blends seal conventions and reinforce the status quo. In other words, they are ideological achievements.

This being so, analogical mappings between the natural universe and the cultural world can be an efficient means of cognitive control and cultural conformity only if they are related one way or another to social organization. We have seen that elaborate and sophisticated organizational forms, such as nations and ethnic groups, can derive from the naturalness of universal social forms, like coalitional alliances. But analogical mappings must come to terms not only with the universal invariants of society but also with the local functioning of the social structure. This claim is particularly well illustrated in Crocker's impressive study of the well-known Bororo statement "We are Parrots" (Crocker, 1977). To Crocker, the analogical connection between "Men" and "Parrots" is grounded in the area of male-female social relationships for only Bororo males are said to be parrots. To explain this specific connection, Crocker shows that parrots are the only kind of domestic pet found among the Bororo, a pet whose ownership is almost entirely limited to women who have 
lost children. Although parrots are said to welcome souls after death, with which they have in common their diet of fish and pale appearance, they are not domestic shrines. As domestic pets, they occupy a position neither wholly animal nor completely human nor sacred creature, while sharing some esteemed and some gross qualities of each. In Crocker's view, the postulate "We are Parrots" is metaphorical of the masculine condition; each man is actually an intruder into the female-dominated household in which he resides, ingests food, enjoys sexuality, procreates and exists on a daily basis. He shares with all other Bororo men the status of ambiguous creatures whose obligations of uterine domicile are in some ways opposed to their residential duties. Bororo rituals normatively emphasize patrifiliation and uterine brotherhood and, since they are mostly forbidden to women, selectively put men under the aegis of the spirits. But this convulsive effort to escape the almost total dominion of women seems hopeless. Even death itself does not transcend the limits of matrilineal domination; once projected upon the domain of spirit, the man's soul is assigned to the responsibility of a woman. "In a very real sense, a Bororo can never leave home. Like a parrot, he is perpetually a child of collective mothers" (Crocker, 1977, p. 191). Analogical mapping between men and parrots thus reveals that both entities are raw material, the temporary vehicle for spirits and social transactions. Like parrots, whose food and sexuality are sought by the spirits, men are used by women for utilitarian ends. Actually, women are exchanging men rather than the reverse: just as they domesticate parrots, they bind masculine loyalties and check their freedom of action.

If, in Crocker's case, the "man/parrot" blend seems to stage and symbolize women's social domination rather than overcome or criticize it, the role of analogical predications can clearly be less doxic and self-perpetuating, that is, more creative. They not only establish and reinforce the what-is of the thing of which they speak but can also create, through unheard-of "sort crossing", new frames of intelligibility (Miller, 1979). For instance, switching from a view of war as deterrence to a view of war as legalized murder makes drastic modifications to the conceptual framework of public debate: it replaces language and thought framing in terms of game with a critical framing of war as a slaughter of human beings - a new "seen as" that provides an alternative way of comprehending things and constrains some specific political solutions. Analogical mappings help to reorganize aspects of reality by enabling us to see some of its aspects as something else - a creative projection that is constitutive of culture and politics (Black, 1979). For culture and politics are not observable directly by the senses; they are constituted by shared analogies and meanings which serve as a "nondefinitional mode of reference fixing" (Boyd, 1979, p. 358). They extend the referential field beyond visible, perceptible things in such a way that cultural and political kinds, that is, unobservable kinds whose real essences consist of complex relational properties, become more familiar, if not intuitive. As Black (1979) put it, metaphors and analogies are ontologically creative: they create things that did not exist before they were perceived and that, once recognized, are truly present. For Black, cultural and political analogies give insights into "how things are", unlike literary metaphors that manifest an odd predilection for asserting a thing to be what it is not; they enable us to see aspects of reality that analogical production helps to constitute. In other words, analogical processing does not compare two things in the world and then locate "out there" their preexistent hidden matches; it is a creative "seeing-as" procedure that forges "family resemblance" between unfamiliar 
events or entities and usual patterns of meaningful experience (Wittgenstein, 1981, §67).

\section{Political inventiveness and ideological naturalization: the French Revolution}

The contribution of analogies and metaphors to conceptual innovation and cultural construction is particularly manifest in the case of the French Revolution, where folk inventiveness led to both the symbolic and the real overthrow of the king's authority (Kaufmann, 2003). At that time, analogical predications had many political implications, whether they took part in the gross expression of humble people or in the alternative model of society elaborated by erudite thinkers. Both erudite and folk theory of politics were indeed very strongly marked by bodily and familial metaphors that were at first actively involved in the tenets serving the monarchical legitimization and then little by little turned upside down by satires and farces trivializing the sacrosanct body of the king.

Actually, the seminal power of the "two bodies of the king", that is, the physical body and the sacred, political body he incarnated, was the symbol of national prosperity (Kantorowicz, 1957). The majesty of the Political Body, whose health and offspring were synonymous with wealth for the realm, depended closely on the health of the natural body in charge of its succession. The king's body was thus an affair of state that demanded the control of the highest authorities and the supervision of the most renowned physicians (de Baecque, 1993). One understands, therefore, how the political chaos arose, at the middle of the eighteen century, through the broad diffusion of the king's counter-portrait in seditious lampoons and bawdy engravings. The meticulous narratives of moral depravity and physical weakness of the king reduced gradually his double body into one single banal body that was no longer anything more than a toy in the hands of his "whores" (Louis XV), or a grotesque body suspected of impotence (Louis XVI) (Darnton, 1982, 1995). As Bakhtin (1968) put it, the "crude physiologism" and the "corporal point of view" peculiar to popular culture challenged the dominant gaps between the high and the low, the close and the far, the private and the public, and the temporal and the spiritual (Bakhtin, 1968). "Grotesque realism", by replacing all spiritual, ideal and abstract things with embodied experience, proclaimed a new cosmological principle: the people's body is the unique and generic guardian of the ultimate power, which is nothing but the reproductive and regenerative power of Nature (Bakhtin, 1968, pp. 28/469).

The fatal implications for the monarchy of the bodily obsessions of public rumors were still intensified by the decline of the paternal figure of the king. The change in familial experiences and unconscious collective images of the familial order - such as father-son, husband-wife and parent-child relations enabled the revolutionary political constructions to break with the patriarchal ideology of absolutism and to promise the patriotic rule of fraternal solidarity within the "Mother-nation" (Hunt 1992). In the leading "familial romances" of the 18th century, the Father-patriarch figure declined in favor of the autonomization of the action field of children whose orphan or foundling status no longer prevented their carving out a place in the social world. Thus, during the Revolution, bodily and familial analogical mappings had serious consequences. They opened a new field of practices, such as the institutionalization of an acephalous Republic and the decisive "acting out" going with it: the 
disappearance of the king's political and natural bodies in favor of the new spirit of the nation, that is, public opinion. Thanks to their phenomenological roots but also to their previous political use in the monarchical regime, bodily and familial analogies allowed a gestalt switch from the waning figure of the King to the rising figure of the Nation.

This example shows how analogies drawing on intuitive knowledge, such as corporal boundaries and physiological needs, are instantly comprehensible and thereby trigger a "taking-for-granted" stance: every single individual is able to project what he or she knows "from the inside" onto the complex and apparently exogenous functioning of collective life. As the highest common denominator of a given community, the mundane obviousness of the ordinary life facilitates the folk appropriation and comprehension of abstract constructs (Kaufmann, 2003). The example of the French revolution also shows that, if the phenomenological source domain of cognition is universal enough to set up a basic ontological complicity between ordinary agents, it is also heavy enough to facilitate the naturalization of a new political world-view in individual minds. By stirring up the "space of experience" and the "horizon of expectation" of ordinary agents to their advantage, a previously unrealistic and impossible world can gradually become a possible, or even familiar, world (Koselleck 1985). In September 1793, indeed, once the people was seen as a collective individual whose will had to be naturally unanimous, particular wishes looked like the immoral, destructive and corrupted parts of the social body. By making disagreement and discord synonymous with the collapse of the social body, the revolutionaries took "the physiological argument" literally enough to behave as physicians who had the duty to diagnose and to cure social pathologies (de Baecque, 1993). By naturalizing politics and turning it into therapeutics, the literalization of bodily analogies led to "the generalized anthropophagy" of the Terror. It transformed the interpretative inferences contained in intuitive analogies into an outright ideology, in the double sense of ideal intensification of experience and naturalization of political abstraction.

\section{CONCLUSION: CULTURAL OPTICS}

On the ontological side, the social naturalism we defend here hypothesizes the existence of social forms that would be the universal ground for cultural elaboration and normative constructs. The "natural meaning" of those elementary social forms is the mediation, the intermediate layer that bridges the gap between natural constraints and artificial cultural systems. On the cognitive side, social naturalism emphasizes: (1) the importance of a quasi-perceptual system of inferences, namely naive sociology, dedicated to the processing of group-level, socially relevant traits; and (2) the prevalence of analogy-making as a device for creating and identifying the overall cultural pattern that gives common resonance to heterogeneous domains of knowledge and integrates them into new conceptual blends. Analogy-making can thus be seen as the basic cognitive operation that forges and holds together the relational networks constituting the essence of human culture.

Our emphasis on the intuitive share of culture, established and enacted thanks to the analogical stretch of phenomenological experience, ordinary conceptualization and social categorization, differs in several respects from the counterintuitive account of culture as a series of evocative, semi-propositional riddles. First, unlike counterintuitive representations, intuitive analogies are not insulated propositions; most of them are unconscious frames of thought and 
latent patterns for action that culture bearers convey through gestures rather than through isolated, expressible propositions. Cultural propositions are only the tip of a system of submerged cross-references that functions, so to speak, as a "pinball machine": once involved in a relational system that makes sense immediately, community members can hardly isolate a single cultural claim (unless this claim is an official tenet, a public utterance that is not necessarily, as such, believed in or put into practice). In other words, making cultural assumptions explicit requires members to be able to distance themselves from the culture they belong to. Now this distance is relatively rare. Most of the time, primary, generative mappings are so embedded in the cultural system that only cognitive archaeology, anthropology and cultural history are capable of retrieving and individuating them. This embedding is not very surprising since forgetting the origins of cultural meanings is a mark of tradition, which is nothing but the rehearsal of habits and practices that are no longer justified - if they were ever justified at all. Given the autonomization and institutionalization of analogical blending and the progression towards oblivion of their original justification, if any, tracking down the third variable that establishes in which respect their source and target domains can be seen as similar is often impossible, just as in Hirschfeld (2000)'s example of carved lions and kinship exchange.

Second, unlike the counterintuitive model of culture, our intuitive model insists on the analogical workings of the mind in virtue of which cultural elaborations become "quasi-perceptible". Drawing from the cognizance of our senses, social commonsense included, analogical mapping is the "continuist glue" that transfers intuition, if not perception, from usual patterns of meaningful experience to unfamiliar events or obscure entities. Admittedly, the intuitive creation and reappropriation of cultural constructs retain an artificial dimension, due to the work of the imagination necessary for entertaining representations that are somewhat unfaithful to the way the world really is. But we have seen that artificiality is not synonymous with arbitrariness in the sense of mere product of unfounded will: analogical blends are grounded in social affordances that cannot be said to be artificial constructs per se since their use is not restricted to mankind. Social regularities can indeed be found in a more rudimentary form in non-human societies whose orderliness, impressive as it may be, is generally characterized as not cultural - at least if we characterize, with Searle (1995), culture as the institution of new "count-as" (i.e. "this red line on the ground" counts as "a border"). Thanks to the quasi-naturalness of the social affordances they derive from, cultural affordances such as analogical relationships have a solid ontological scaffolding.

As seen above, the naturalization process that leads to the quasi-perceptive status of analogical mapping is twofold. From an analytical viewpoint, it refers either to the ideological, "top-down" naturalization of cultural analogies that descend into the background of tacit knowledge of community members; or to the phenomenological, "bottom-up" extension of intuitive expectations that ascend from hard-wired assumptions. Of course, from an empirical viewpoint, the two senses of this naturalization process are almost impossible to separate: analogy-making spirals up and down to make cultural abstractions nature-like. Moreover, the two senses of naturalization head in the same direction: both show that social forms and cultural constructs are closer to one another than the model of culture as an imaginative leap tends to suggest. For culture can also be seen from the angle of affordances, that is, the organization of attention. 
Culture largely consists of attentional commonalities that mediatize the perception, qualification and recognition of salience, define what information is relevant in which situation, and inhibit opportunities for action. Although perceivers do identify, independently of the culture they belong to, the same informational basis in social affordances such as comforting, fighting or sharing, they consider certain kinds of relationship as more salient than others. The differential degree of salience that social objects are endowed with is then at the heart of the process of enculturation: it results from the "attentiondirecting interactions" of attention holders, mainly caregivers, who lead the child to discover, in the layout of his or her environment, the culturally hierarchized scope of choices and sense of possibilities (Loveland, 1991). Individuals thus discover the cultural affordances of events, relationships and objects through the acquisition of information furnished by their environment, for instance that a given meat is taboo or that an intimate relationship is shameful. From this ecological perspective, cultural competence is not a matter of decoding the meaning of a proposition, but a matter of singling out particular aspects of the environment for scrutiny and action and screening others as irrelevant (Windsor, 2004). Like physical objects, primitive social affordances can be culturally invested and transformed according to the kind of attentional focus they are subjected to. From merely recognizable gestalts, social affordances can turn into cultural "good forms", that is, valued objects of joint attention and social referencing. The fact that the grasp of something as an opportunity for action and the attention to some objects rather than others vary across cultures is particularly well demonstrated in the groundbreaking work of Richard Nisbett (Nisbett \& al., 1999; Nisbett, 2004). In various experiments synthesized in Nisbett et al. (this volume), it was observed that Easterners give priority to relationship processing, background elements and holistic explanations whereas Westerners focus on individual properties, mentalistic attributions and analytic thinking. Anthropology and cultural psychology have also shown that certain cultures are much more attendant to situational features than to various internal mental states, whether activated or dispositional, when explaining others' behaviors (see Lillard, 1998, for reviews). A large amount of evidence thus shows cultural variation in the degree of salience of social affordances, such as relationships, situations or rules, and in the role that those affordances play in the prediction and explanation of behaviors.

From this Gestaltic perspective, human beings are less organisms that acquire "cultural contents" through specific devices than perceptual systems that learn to "be affected" through the "education of attention" (Gibson, 1979, p. 254; Servais, this volume). As Zerubavel (1997) put it, optical enculturation teaches us how to "look" at things in a certain conventional way, which explains the relatively small number of optical deviants who dare to defy or ignore the optical norms of their social environments by maintaining a view of the world that is at odds with the one commonly shared by others around them and by thereby risking a cognitive - and social - excommunication. If we consider culture as an attentional system that gives individuals the incentive to recognize some social affordances as worthy of being acted upon, it is no wonder that natives "see" the analogical mappings that make sense of their society as a whole without being able to justify them. As building blocks of the participative and quasi-perceptive world of culture, analogies are the bearers of socio-cultural relevance, not of ontological truth. 


\section{REFERENCES}

Atran S., Medin D.L, Ross N.O (2005). The Cultural Mind: Environmental Decision Making and Cultural Modeling Within and Across Populations. Psychological Review, 112 (4), pp.744-776

Atran, S. (1990). Cognitive Foundations of Natural History: Towards an Anthropology of Science. Cambridge, England: Cambridge University Press.

Atran, S. (2002). In Gods We Trust. The Evolutionary Landscape of Religion. Oxford: Oxford University Press.

Baillargeon, R. (1987). Object Permanence in 31/2 and 41/2-months-old Children, Developmental Psychology, 23, pp.655-664.

Bakhtin, M. (1968). Rabelais and his World. Bloomington: Indiana University Press

Baron-Cohen, S. (1995). Mindblindness. Cambridge, MA: MIT Press.

Bateson, G. (1963). A Social Scientist Views Emotions. In P.H., Knapp (ed.), Expression of the Emotions in Man. New York: International University Press, pp. 230-236.

Bazin, J. (1991). Les fantômes de Mme du Deffand: exercices sur la croyance. Critique, $n^{\circ}$ 529-530, pp. 492-511.

Black, M. (1955). Metaphor. Proceedings of the Aristotelian Society, 55, pp.273-294

Black, M. (1979). More About Metaphor. In A. Ortony (ed.), Metaphor and Thought. Cambridge: Cambridge University Press, pp.19-43.

Boesch, C. \& Tomasello, M. (1998). Chimpanzee and Human Cultures. Current Anthropology, 19 (5), pp. 591-614.

Boyd, R. (1979). Metaphor and Theory Change: What is "Metaphor" a Metaphor for? In A., Ortony (ed.), Metaphor and Thought. Cambridge: Cambridge University Press, pp.356-408

Boyer, P. (1994). The Naturalness of Religious Ideas: Outline of a Cognitive Theory of Religion. Los Angeles: University of California Press.

Boyer, P. (2001). Religion Explained. The Evolutionary Origins of Religious Thought. New York: Basic Books.

Bruner, J. (1990). Acts of Meaning. Cambridge-Mass: Harvard University Press.

Byrne, R.W. \& Whiten, A. (ed.) (1988). Machiavellian Intelligence: Social Expertise and the Evolution of Intellect in Monkeys, Apes, and Humans. Oxford: Oxford University Press.

Carrithers, M. (1997). Culture. In T., Barfield (ed.), The Dictionary of Anthropology. Oxford: Blackwell.

Céfaï, D. (2001). Le naturalisme dans la sociologie américaine au tournant du siècle. Revue du Mauss, 17, pp. 261-274

Cheney, D. L. \& Seyfarth. R. M. (1990). How Monkeys See the World. Chicago: University.

Clifford, J. (2002). The Predicament of Culture: Twentieth-Century Ethnography, Literature, and Art. Harvard University Press.

Collin, F. (1997). Social reality. London /New York: Routeledge.

Conein, B. (2001). Le sociologue dans la nature. Pourquoi pas? Revue du Mauss, 17, pp. 293-301.

Conein, B. (2005). Les sens sociaux. Paris: Economica.

Cosmides, L. \& Tooby, J. (1994). Origins of Domain Specificity: The Evolution of Functional Organization. In L.A., Hirschfeld \& S.A., Gelman, Mapping the Mind. Domain Specificity in Cognition and Culture. Cambridge: Cambridge University Press, pp. 85-116.

Costall, A. (1995). Socialising Affordances. Theory \& Psychology, 5, pp. 467-482.

Crocker, J.C. (1977). My Brother the Parrot. In J.D., Sapir \& J. C., Crocker (dir.), The Social Use of Metaphor. Essays on the Anthropology of Rethoric. Pennsylvania: University of Pennsylvania, pp. 164-192.

Darnton, R. (1982). The Literary Underground of the Old Regime. Cambridge: Harvard University Press. 
Darnton, R. (1995). The Forbidden Bestsellers of Pre-revolutionary France. New York/London: W.W. Norton.

Davidson, D. (1978). What Metaphors Mean. Critical Inquiry, 5 (1), pp. 31-47

De Baecque, A. (1993). Le corps de l'histoire: Métaphores et politique (1770-1800). Paris: Calmann-Lévy.

De Waal, F. B. (1991). The Chimpanzee's Sense of Social Regularity and its Relation to the Human Sense of Justice. American Behavioral Scientist, 34, pp. 335-349.

De Waal, F., \& Filippo, A. (1996). Consolation, Reconciliation, and a Possible Cognitive Difference Between Macaques and Chimpanzees. In A. E., Russon, K. A., Bard, \& S., Taylor Parker (eds.), Reaching into Thought. The Minds of the Great Apes. Cambridge: Cambridge University Press, pp. 80-110.

Dedrick, D. (2005). Color, Color Terms, Categorization, Cognition, Culture: An Afterword. Journal of Cognition and Culture, 5(3), pp. 487-495.

Descola, P. (2005). Par-delà nature et culture. Paris: Gallimard.

Descombes, V. (1996). Les institutions du sens. Paris: Minuit.

DiMaggio, P. (1997). Culture and Cognition. Annual Review of Sociology, 23, pp. $263-$ 288

DiSessa, A.A (1983). Phenomenology and the Evolution of Intuition. In D., Gentner and A. L., Stevens (eds), Mental Models. Hillsdale: NJ, Erlbaum, pp.15-33.

Douglas, M. (1986). How Institutions Think. Syracuse University Press.

Dunbar, R., Knight, C. \& Power, C. (1999). An Evolutionary Approach to Human Culture. In R., Dunbar et al. (ed), The Evolution of Culture. An interdisciplinary view. New Jersey: Rutgers University Press, pp. 1-11

Duncan, S. \& Farley, A.M. (1990). Achieving Parent-Child Coordination through Convention: Fixed- and Variable-Sequence Conventions. Child Development, pp.742-753.

Dupuy, J-P. (1989). Convention et Common knowledge. Revue économique, 2, pp. 361-400.

Durkheim, E. (1991). Les formes élémentaires de la vie religieuse. Librairie Générale Française [1 $1^{\text {ère }}$ éd. 1912].

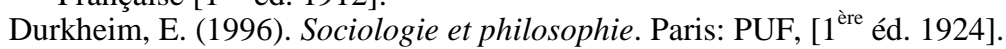

Esfeld, M. (1998). Holism and Analytic Philosophy. Mind, 107, pp. 365-380.

Evans-Pritchard, E.E. (1956). Nuer religion. Oxford: Oxford University Press.

Fauconnier, G. \& Turner, M. (1998). Conceptual Integration Networks. Cognitive Science, 22 (2), pp. 133-187.

Fauconnier, G. (1997). Mappings in Thought and Language. New York: Cambridge University Press.

Fay, B. \& Moon, J.D. (1977). What Would an Adequate Philosophy of Social Science Look Like? Philosophy of the Social Sciences, 7, pp. 227-241.

Fernandez, J.W. (1974). The Mission of Metaphor in Expressive Culture. Current Anthropology, 15 (2), pp. 119-133.

Fernandez, J.W. (1977). The Performance of Ritual Metaphors. In J.D., Sapir and J.C., Crocker (ed), The Social Use of Metaphor. Essays on the Anthropology of Rhetoric. Pennsylvania: University of Pennsylvania Press, pp.100-131.

Flack, J., Jeannotte, L., \& de Waal, F. (2004). Play Signaling and the Perception of Social Rules by Juvenile Chimpanzees (Pan Troglodytes). Journal of Comparative Psychology, 118 (2), pp. 149-159.

Foucault, F. (1971). Nietzsche, la généalogie, l'histoire. In Hommage à Jean Hyppolite. Paris: PUF, pp. 145-172.

Gabennesch, H. (1990). The Perception of Conventionality by Children and Adults. Child Development, 61, pp. 2047-2059.

Geertz, C. (1973). The Interpretation of Cultures. New York: Basic Books.

Geertz, C (1975). "From the Native's Point of View": On the Nature of Anthropological Understanding. American Scientist, 63, pp. 47-53.

Gelman, R. \& Williams, E. M. (1998). Enabling Constraints for Cognitive Development and Learning: Domain Specificity and Epigenesism. In D., Kuhn, \& 
R. S., Siegler (dir.), Handbook of child psychology, vol. II (fifth ed.). New York: Wiley, pp. 575-630.

Gentner, D. et al. (2001a). Introduction: The Place of Analogy in Cognition. In D., Gentner et al. (dir.), The Analogical Mind. Perspectives from Cognitive Science. Cambridge, Mass/London, England: MIT Press, pp. 1-19.

Gentner, D. et al. (2001b). Metaphor is Like Analogy. In Gentner, D. et al. (dir.), The Analogical Mind. Perspectives from Cognitive Science. Cambridge/Mass, London: MIT Press, pp. 199-253.

Gentner, D. et al. (2001c). The Analogical Mind. Perspectives from Cognitive Science. Cambridge, Mass/London: England, MIT Press.

Gibson, J. (1979). The Ecological Approach to Visual Perception. Boston: Houghton Mifflin Company.

Giere, R.N. (2000). Naturalism. A Companion to the Philosophy of Mind. London: Blackwell, pp. 308-310.

Goldie P. (2007). Seeing What is the Kind of Thing to Do: Perception and Emotion of Morality. Dialectica, in press.

Good, J.M (2007). The Affordances for Social Psychology of the Ecological Approach to Social Knowing. Theory \& Psychology, 17 (2), pp. 265-295.

Goodall, J. (1983). Order without Law. In M., Gruter and P., Bohannan (eds.), Law, Biology, and Culture: The Evolution of Law. Santa Barbara: CA, Ross-Erickson, pp. 50-62.

Goswami, U. (1991). Analogical Reasoning in Children. Hillsdale: Lawrence Erlbaum Associates.

Grice, P. (1957). Meaning. Philosophical Review, 66, pp. 377-88.

Harris, P. (2000). The Work of the Imagination. Oxford: Blackwell Publishers Ltd.

Hirschfeld, L.A \& Gelman, S.A (1994). Mapping the Mind. Domain Specificity in Cognition and Culture. Cambridge: Cambridge University Press.

Hirschfeld, L.A (2000). Analogy and the Problem of Cultural Meaning. Paper presented on Invited Panel in Honor of Jerome Bruner, Annual Meetings of the American Anthropological Association, San Francisco, CA.

Hirschfeld, L.A. (1995). Do Children Have a Theory of Race? Cognition, 54, pp. 209252.

Hirschfeld, L.A. (1996). Race in the Making: Cognition, Culture, and the Child's construction of Human Kinds. Cambridge Mass./London-England: MIT Press.

Hofstadter, D.R. (2001). Analogy as the Core of Cognition. In D., Gentner et al. (dir.), The Analogical Mind. Perspectives from Cognitive Science. Cambridge, Mass/London, England: MIT Press, pp. 499-538.

Holyoak, K. \& Thagard, P. (1997). The Analogical Mind. American Psychologist, 52 (1), pp. 35-44.

Hunt, L. (1992). The Family Romance of the French Revolution. Berkeley/Los Angeles: University of California Press.

Ingold, T. (2001). From the Transmission of Representations to the Education of Attention. In H., Whitehouse (ed.), The Debated Mind. Oxford New York: Berg, pp. 113-153.

Jackendoff, R.S. (1992). Languages of the Mind: Essays on Mental Representation. Cambridge: MIT Press.

Johnson, M. (ed) (1981). Philosophical Perspectives on Metaphor. Chicago: University of Chicago Press.

Kantorowicz, E. (1957). The King's Two Bodies: A Study in Mediaeval Political Theology. Princeton, New Jersey: Princeton University Press.

Kaufmann L. \& Clément F. (2003). La sociologie est-elle un savoir infus? De la nature sociale de l'architecture cognitive. Intellectica, 36-37, pp. 421-457.

Kaufmann, L. (2003). In Search of a Cultural "Common Denominator". Metaphors, Historical Change and Folk Metaphysics. Social Science Information, 42 (1), pp. 107-142.

Kaufmann, L. (2006). Les voies de la déférence. De la nature des concepts sociopolitiques. Langage et Société, 117, pp. 89-116. 
Keil, F. (1989). Concepts, Kinds, and Cognitive Development. Cambridge MA: MIT Press.

Koffka, K. (1935). Principles of Gestalt Psychology. New York/Harcourt: Brace World

Koselleck, R. (1985). Futures Past: On the Semantics of Historical Time. Cambridge: MIT Press.

Lakoff, G. \& Johnson, M (1980). Metaphors We Live By. Chicago: The University of Chicago Press.

Lakoff, G. \& Johnson, M (1999). Philosophy in the Flesh: The Embodied Mind and its Challenge to Western Thought. New York: Basic Books.

Levin, S.R. (1979). Standard Approaches to Metaphor and a Proposal for Literary Metaphor. In A., Ortony (ed.), Metaphor and Thought. Cambridge: Cambridge University Press, pp.124-135

Lévy-Bruhl, L. (1938). L'Expérience mystique et les symboles dans la mentalité primitive. Paris: Alcan.

Lewis, D.K. (1969). Convention. A Philosophical Study. Cambridge: Harvard University Press.

Lewis, D.K. (1993). Langages et langage. Réseaux, 62, CNET, pp. 9-18.

Lillard, A. (1998). Ethnopsychologies: Cultural Variations in Theories of Mind. Psychological Bulletin, 123 (1), pp. 3-32

Loveland, K. (1991). Social Affordances and Interaction II: Autism and the Affordances of the Human Environment. Ecological Psychology, 3 (2), pp. 99-119.

Mayr, E. (2004). What makes Biology unique? Cambridge: Cambridge University Press.

Meltzoff, A.N. \& Brooks, R. (2001). "Like Me" as a Building Block for Understanding Other Minds: Bodily Acts, Attention, and Intention. In B.F., Malle et al. (ed.), Intentions and Intentionality: Foundations of Social Cognition. Cambridge, Mass.: MIT Press, pp. 171-191

Miller, E.F. (1979). Metaphor and Political Knowledge. The American Political Science Review, 73 (1), pp. 155-170

Nisbett, R.E et al. (1999). Causal Attribution Across Cultures Variation and Universality. Psychological Bulletin, 125 (1), pp. 47-63.

Nisbett, R.E. (2004). The Geography of Thought: How Asians and Westerners think differently... and why. New York, Free Press.

Park, R.E. (1936). Human Ecology. American Journal of Sociology, 42, pp. 1-15

Pomerantz, J.R. (2003). Perception. In L., Nadel (ed.), Encyclopedia of Cognitive Science. London: Nature Publishing Group, pp. 527-537.

Premack, D. \& Premack A. (2002). Original Intelligence Unlocking the Mystery of Who We Are. New York: McGraw-Hill.

Quéré, L. (1993). A-t-on vraiment besoin de la notion de convention? Réseaux, 62, pp. 21-42.

Quéré, L. (1999). Action située et perception du sens. In M., de Fornel \& L., Quéré (dir.), La logique des situations. Raisons Pratiques 10, pp. 301-338.

Quéré, L. (2001). Naturaliser le sens: une erreur de catégorie? Revue du Mauss, 17, pp. 275-292.

Quéré, L. (2002). La validité de l'argument naturaliste en sciences sociales. Enquête, 2, pp. 93-117.

Ramachandran V.S and Blakeslee, S. (1999). Phantoms in the Brain: Probing the Mysteries of the Human Mind. Fourth Estate.

Reed, E. (1996). Encountering the World: Toward and Ecological Psychology. Oxford: Oxford University Press.

Rosenthal, V. \& Visetti, Y-M. (1999). Sens et temps de la Gestalt. Intellectica, 28, pp. 147-227.

Rosenthal, V. \& Visetti, Y-M. (2003). Köhler. Paris: Les Belles Lettres.

Sanders, J.T.(1997). An Ontology of Affordances. Ecological Psychology, 9 (1), pp. 97-112.

Schmidt, R.C. (2007). Scaffolds for Social Meaning. Ecological Psychology, Vol. 19, No. 2, pp. 137-151 
Searle John R. (1995). The Construction of Social Reality. Allen Lane: The Penguin Press.

Searle, J. (1979). Expression and Meaning. Cambridge: Cambridge University Press.

Searle, J. (1983). Intentionality. An Essay in the Philosophy of Mind. Cambridge: Cambridge University Press.

Spelke, E. \& Dehaene S. (1999). Biological Foundations of Numerical Thinking. Trends in Cognitive Sciences, 3 (10), pp. 365-366

Sperber, D. \& Hirschfeld, L. (1999). Culture, Cognition, and Evolution. In R.A., Wilson and F.C., Keil, (ed.), The MIT Encyclopedia of the Cognitive Sciences (MITECS). Cambridge, Mass.: MIT Press.

Sperber, D. (1975). Rethinking Symbolism. Cambridge/New York: Cambridge University Press.

Sperber, D. (1996). Explaining Culture: A Naturalistic Approach. Oxford: UK/Cambridge, Mass.. Blackwell.

Stavros Valenti, S. \& Gold, J.M. (1991). Social Affordances and Interaction I: Introduction. Ecological Psychology, 3 (2), pp. 77-98 .

Tomasello, M. (1999). The Human Adaptation for Culture. Annu. Rev. Anthropol., 28, pp. 509-529.

Tooby, J. and Cosmides, L. (1992). The Psychological Foundations of Culture. In J. H., Barkow, L., Cosmides and J., Tooby (eds.), The Adapted Mind: Evolutionary Psychology and the Generation of Culture. Oxford University Press.

Tuomela, R. (1995). The Importance of Us. A Philosphical Study of Basic Social Notions. Stanford: Stanford University Press.

Turner, M. (2001). Cognitive Dimensions of Social Science. The Way We Think About Politics, Economics, Law, and Society. Oxford: Oxford University Press.

Turner, T. (1991). "We are parrots", "Twins are birds". Play of Tropes as Operational Structure. In J.W., Fernandez (ed.), Beyond Metaphor. The Theory of Tropes in Anthropology. Stanford: Stanford University Press, pp.121-158

Turvey, T et al. (1981). Ecological Laws of Perceiving and Acting. Cognition, 9, pp. 237-304

Tylor, E.B. (1958). Religion in primitive culture. New York: Harpers \& Brothers.

Wellman, H. (1990). The Child's Theory of Mind. Cambridge: MA, MIT Press.

Windsor, W. L. (2004) An Ecological Approach to Semiotics. Journal for the Theory of Social Behaviour, 34 (2), pp. 179-198

Wittgenstein, L. (1981). Philosophical Investigations. Oxford: Blackwell [1 ${ }^{\text {ère }}$ éd. 1953].

Zerubavel, E. (1997). Social Mindscapes. An Invitation to Cognitive Sociology. Cambridge: Harvard University Press. 